\title{
Mixed Fermentation with Metschnikowia pulcherrima Using Different Grape Varieties
}

\author{
Filomena L. Duarte 1,2,*, Ricardo Egipto ${ }^{1,3}$ and M. Margarida Baleiras-Couto ${ }^{1,2}$ \\ 1 Instituto Nacional de Investigação Agrária e Veterinária, INIAV-Dois Portos, Quinta da Almoínha, \\ 2565-191 Dois Portos, Portugal \\ 2 University of Lisboa, Faculty of Sciences, BioISI - Biosystems \& Integrative Sciences Institute, \\ 1749-016 Lisboa, Portugal \\ 3 LEAF-Linking Landscape, Environment, Agriculture and Food, Instituto Superior de Agronomia, \\ Universidade de Lisboa, Tapada da Ajuda, 1349-017 Lisboa, Portugal \\ * Correspondence: filomena.duarte@iniav.pt; Tel.: +351-261-712-500
}

Received: 13 June 2019; Accepted: 1 July 2019; Published: 8 July 2019

\begin{abstract}
The study and use of non-Saccharomyces yeasts to wine improvement and diversification has gained considerable relevance in recent years. The present work reports a pilot-scale winery assay of mixed fermentation with a commercial strain of Metschnikowia pulcherrima, tested in five white and nine red grape varieties. Two modalities were assayed, one with the addition of M. pulcherrima at time zero and addition of Saccharomyces cerevisiae after $24 \mathrm{~h}$, and a control using only S. cerevisiae at time zero. Fermentation was monitored by daily measurement of density and temperature. Wine physicochemical analysis was performed after winemaking and repeated after four years of aging. Variance and multivariate analysis were used to examine these data. Triangle and ranking tests were performed on the wines obtained, using an experienced sensory panel. Alcoholic fermentation proceeded smoothly until there was complete consumption of the sugars. M. pulcherrima in mixed fermentation, although mainly recommended for white wine, was also tested for red wines. These wines generally presented higher glycerol, reducing sugars and total dry matter, and lower alcohol content, in line with the current market trend. Significant sensory differences among modalities were only obtained for three varieties. Results emphasized that grape variety is a relevant factor in studies with non-Saccharomyces yeasts.
\end{abstract}

Keywords: mixed fermentations; Metschnikowia pulcherrima; wine; grape variety; sensory analysis

\section{Introduction}

The benefits of adding non-Saccharomyces yeasts in wine production are the focus of a great deal of studies among wine yeast researchers, the sensory characteristics assuming particular importance [1-3]. Consumer demand for wines with increased diversity has been its major driving force and has even motivated the industry to bring to market a large number of products with non-Saccharomyces yeasts.

The fermentation process using mixed cultures, with sequential addition of non-Saccharomyces yeasts and $S$. cerevisiae, tends to mimic spontaneous fermentations, especially in terms of population dynamics. M. pulcherrima is one of the species most detected in the initial phase of alcoholic fermentation of grape musts [4]. Several works have shown greater production of higher alcohols, namely isobutanol, in fermentations with the addition of M. pulcherrima, and although these compounds, in very high content, have negative notes, in moderate levels they contribute for the wine's complexity $[3,5]$. Higher fatty acids content was observed by Comitini et al. [6] and Liu et al. [5] and they also observed an increase in $\beta$-damascenone. The higher level of esters obtained in fermentations with M. pulcherrima is mainly due to higher isoamyl acetate content, contributing to higher fruity aromas [3,5-7]. On the 
contrary, there are studies indicating similar sensory characteristics in wines fermented with $S$. cerevisiae in single or in co-culture with $M$. pulcherrima $[3,8]$. More consensual is the higher glycerol content of wines produced in a mixed culture with M. pulcherrima [2,5,6]. Du Plessis et al. [9] also emphasized the choice of the malolactic fermentation strategy that should be matched with the non-Saccharomyces strain/species used, and thus, obtaining complete malolactic fermentations and more complex wines.

The production of wines with lower alcohol content has been sought out using non-Saccharomyces yeasts, namely M. pulcherrima in co-inoculation, with a significant reduction in alcohol content and good sensory profile, similar to fermentation with S. cerevisiae [8,10]. Nevertheless, Chen et al. [3] obtained wines with higher ethanol content. Several authors do remark on the variability of characteristics related to the strain evaluated, pointing out the potential of species previously set aside based on single strain evaluations [2,11].

Most of the aforementioned works were conducted in laboratory fermentations using synthetic or sterilized must from a single grape variety, conditions that are quite distant from real winery environments. Additionally, there is a lack of studies on non-Saccharomyces yeasts using various grape varieties in the same fermentation conditions, as in general, each work reports the use of only one variety [12].

The present work reports a mixed fermentation assay with a commercial M. pulcherrima strain performed in pilot-scale winery conditions and tested in fourteen different grapevine varieties. The effect of fermentation with M. pulcherrima over physicochemical and sensory differences of the wines was evaluated. A general trend of the wines produced in mixed fermentation with M. pulcherrima was the higher values of total dry matter, glycerol and reducing sugars and lower alcoholic strength observed. However, sensory differences were only observed for three grape varieties. This work emphasizes the grape variety as an important factor, not always considered in studies with non-Saccharomyces yeasts.

\section{Materials and Methods}

The white varieties Fernão Pires (FP), Seara Nova (SN), Alvarinho (Alv), Verdelho (Ver) and Viognier (Vio) and the red varieties Merlot (Me), Jaen (J), Caladoc (Cal), Syrah (Sy), Castelão (Cast), Touriga Nacional (TN), Aragonês (Ar), Tinta Barroca (TB) and Cabernet Sauvignon (CS) were harvested from INIAV-Dois Portos Experimental Station vineyard in 2013.

Red and white grapes were crushed, destemmed and added with $20-30 \mathrm{mg} / \mathrm{L}$ of sulphur dioxide (potassium metabisulfite), depending on the sanitary state of the grapes. Red grapes were added with pectolytic enzymes (pectin liase $>85 \mathrm{U} / \mathrm{g}$; pectin methyl esterase $>620 \mathrm{U} / g$; polygalacturonase $>$ $3100 \mathrm{U} / \mathrm{g}$ ), to increase color and tannin extraction, were thoroughly homogenized and equally divided into two stainless steel vats of 50-60 L. White grapes were added with pectolytic enzymes (pectin liase $>80 \mathrm{U} / g$; gluconidase > $24 \mathrm{U} / g$; polygalacturonase $>3200 \mathrm{U} / \mathrm{g}$ ), to improve extraction of aroma and aroma precursors. They were pressed and the juice clarified by cold settling for $24 \mathrm{~h}$ and then also equally distributed into two stainless steel deposits of 50-60 L. Each deposit corresponded to one of the modalities assayed: $\mathrm{Mp}$ —with the addition of commercial M. pulcherrima at time zero and the addition of S. cerevisiae after $24 \mathrm{~h}$; C-addition of $S$. cerevisiae at time zero, used as a control. Duplicates of each modality were performed for Touriga Nacional, Aragonês and Syrah grapevine varieties. For red grapes, commercial lactic acid bacteria (Oenococcus oenii) was added $24 \mathrm{~h}$ after S. cerevisiae. Fermentation proceeded under a controlled temperature, $16^{\circ} \mathrm{C}$ for white wines and $22^{\circ} \mathrm{C}$ for red wines, and progress was monitored by daily measurement of density and temperature after homogenization. At mid fermentation, a blend of yeast nutrients was added (composed of ammonium salts, organic nitrogen, vitamins, minerals, sterols and polyunsaturated fatty acids for white wines; and composed of inactivated yeast cells, diammonium phosphate (DAP) and diammonium sulphate, thiamine and silica gel for red wines). After the end of fermentation, red grape seeds and skins were separated from the wine and racking was performed several times both to red and to white wine. Before bottling, commercial potassium metabisulfite was added to the wine to obtain a free sulfur dioxide content of $35 \mathrm{mg} / \mathrm{L}$. Bottled wine was stored in a cave at a temperature around $18{ }^{\circ} \mathrm{C}$. 
Physicochemical analysis of grape must from each variety was performed. The $\mathrm{pH}$ was measured by potentiometry (OIV-MA-AS-313-15), total acidity (as g tartaric acid $\mathrm{L}^{-1}$ ) was determined by acid-base titration (OIV-MA-AS313-01) and sugar content $\left(\mathrm{g} . \mathrm{L}^{-1}\right)$ and mass density at $20^{\circ} \mathrm{C}$ were calculated by refractometry (OIV-MA-AS2-02) from the refractive index at $20^{\circ} \mathrm{C}$ [13].

Wine analysis, namely alcoholic strength (AS), specific gravity (SG), total dry matter (TDM), reducing sugars (RS), total acidity (TA), volatile acidity (VA), glycerol (Gly), pH and total polyphenol index (IPT), was performed by Fourier transform infrared spectroscopy (FTIR) using the WineScan FT120 (Foss, Denmark). Analysis was performed in 2014 and 2018.

Statistical analysis of two-Way ANOVA, using the variety (Ar, TN and Sy) and the Mp treatment as factors, was performed with the software Statistix (version 9, Analytical Software, USA). A principal component analysis (PCA) on FTIR data was also computed using STATISTICA (version 13.3, TIBCO Software Inc).

Discrimination sensory analysis, including triangle tests and ranking tests, were performed. Both tests use a forced-choice procedure. The sensory analysis took place in a standardized tasting room with individual white boots, using standard wine-tasting glasses (ISO 3591:1977) filled with $30 \mathrm{~mL}$ of wine and covered with half of a glass petri dish. The analysis was carried out by an expert panel of twelve wine tasters (eight female and four male) aged between 29 and 62 years. White wines were served between 8 and $10^{\circ} \mathrm{C}$ and red wines between 16 and $18^{\circ} \mathrm{C}$.

Triangle tests to determine whether a perceptible sensory difference exists between $\mathrm{Mp}$ and $\mathrm{C}$ wines were performed according to ISO 4120:2004. The six possible orders of the two wines were presented equally. Each pair of wines was analyzed in two different sessions, in order to have 18 evaluations, the minimum number required when testing for difference. The repetitions were summed as independent results [14] and the outcome value compared with the table provided by the ISO 4120:2004. Ranking tests were conducted for modalities with duplicates (Touriga Nacional, Aragonês and Syrah), presenting at the respective session the four wine samples in balanced orders to eliminate first-order carry-over effects [15]. Tasters had to position the wines from lower to higher color intensity, flavor quality, taste quality and overall quality. The positions were converted in punctuations, the lower to one point and the higher to four points, and alike to the middle points. The statistical analysis of the data was based on the calculation of Friedman's coefficient and the result obtained compared with the values of the Chi-squared distribution table [15].

\section{Results and Discussion}

Portuguese wines are traditionally obtained from a great diversity of grapevine varieties. This work envisaged the study of mixed fermentations with S. cerevisiae and M. pulcherrima in five red Portuguese grapevine varieties, namely Castelão, Jaen, Touriga Nacional, Tinta Barroca and Aragonês and four white Portuguese grapevine varieties, namely Fernão Pires, Seara Nova, Alvarinho and Verdelho. International grapevine varieties widespread in Portugal and all over the world such as Merlot, Syrah, Caladoc, Cabernet Sauvignon and Viognier were also tested. Duplicate assays were done to Touriga Nacional, Aragonês and Syrah that are the most widely used varieties in Portugal. Table 1 evidences the diversity of characteristics of the musts obtained.

The influence of M. pulcherrima on the fermentation evolution and wine's characteristics was evaluated. The fermentation progress, represented by temperature and density over time, for two red wine varieties, Merlot and Aragonês, and two white varieties, Alvarinho and Verdelho, are shown in Figure 1 as example. For the duplicate assays with the red grapevine varieties Touriga Nacional, Aragonês and Syrah almost overlapping curves were observed, as is shown for Aragonês (Figure 1). Curves of temperature and density pointed out the one day delay of the addition of Saccharomyces cerevisiae, as fermentation started earlier in the control, showing along the fermentation lower density, but eventually, at the end of fermentation, both modalities attained similar density values. All other fermentation curves showed similar behavior to the ones presented here (results not shown). 
Table 1. Main characteristics of the grape musts.

\begin{tabular}{|c|c|c|c|c|}
\hline Grapevine Variety & $\begin{array}{l}\text { Sugar } \\
\left(\text { g. } L^{-1}\right)\end{array}$ & $\begin{array}{c}\text { Mass Density } \\
\text { at } 20^{\circ} \mathrm{C}\end{array}$ & $\mathrm{pH}$ & $\begin{array}{l}\text { Total Acidity } \\
\text { (g.L } \mathrm{L}^{-1} \text { tart. ac.) }\end{array}$ \\
\hline Fernão Pires & 254.2 & 1.109 & 3.41 & 3.8 \\
\hline Seara Nova & 199.6 & 1.087 & 3.25 & 5.0 \\
\hline Verdelho & 245.1 & 1.106 & 3.33 & 5.4 \\
\hline Viognier & 177.3 & 1.077 & 3.51 & 3.5 \\
\hline Alvarinho & 186.2 & 1.082 & 3.13 & 5.7 \\
\hline Merlot & 258.8 & 1.111 & 3.57 & 7.0 \\
\hline Jaen & 204.1 & 1.089 & 3.66 & 3.4 \\
\hline Caladoc & 224.5 & 1.097 & 3.32 & 5.0 \\
\hline Syrah & 226.7 & 1.098 & 3.39 & 5.6 \\
\hline Castelão & 252.0 & 1.108 & 3.52 & 4.6 \\
\hline Touriga Nacional & 229.0 & 1.099 & 3.41 & 5.6 \\
\hline Aragonês & 222.2 & 1.096 & 3.41 & 4.6 \\
\hline Tinta Barroca & 210.9 & 1.092 & 3.33 & 5.5 \\
\hline Cabernet Sauvignon & 219.9 & 1.095 & 3.35 & 4.0 \\
\hline
\end{tabular}
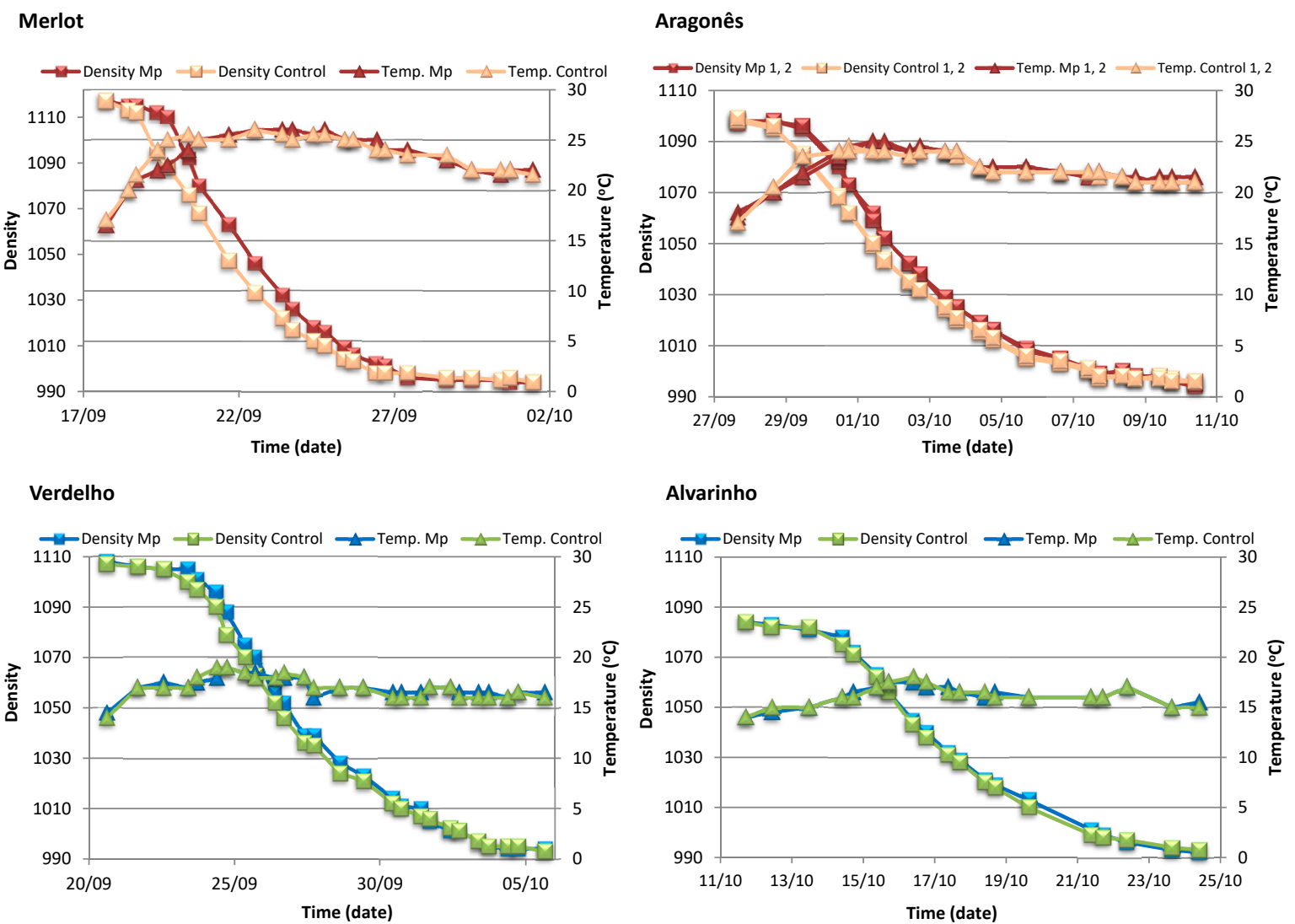

Figure 1. Fermentation curves of Merlot, Aragonês, Alvarinho and Verdelho grape varieties.

For both modalities, alcoholic fermentation proceeded smoothly until complete consumption of the sugars was achieved, corresponding to contents of approximately $2 \mathrm{~g} / \mathrm{L}$ for the sum of glucose and fructose, for all the varieties tested. These values were reached quickly, with fermentations that lasted between 13 and 20 days for the white varieties and between 12 and 16 days for the red varieties. Likewise, for red wines, malolactic fermentation had a rapid completion, almost simultaneously with the alcoholic fermentation (results not shown). 
Physicochemical analysis of the wines was performed in 2014 and repeated in 2018 to evaluate wines evolution. Statistical analysis of two-Way ANOVA, using the variety and the Mp treatment as factors, was performed in order to evaluate the effect of M. pulcherrima on wine chemical attributes. Table 2 presents statistical analysis of the results obtained for red grapevine varieties assayed in duplicate (Touriga Nacional, Aragonês and Syrah). The statistical effect of M. pulcherrima over AS, TDM, RS and Gly was found, either in 2014 or 2018, though with varying levels of significance. Significant effect on SG was observed in 2018, Mp wines presenting higher values. TDM, RS and Gly were also higher in Mp wines in agreement with results observed by other authors [2,5,6]. Accordingly, AS was lower in Mp wines, both in 2014 and 2018. This alcohol reduced content was only around $0.1 \%$ $(\mathrm{v} / \mathrm{v})$, well below the decrease obtained by Varela et al. [8].

Table 2. Two Way ANOVA to evaluate Metschnikowia pulcherrima effect in wine physicochemical parameters using Fourier transform infrared spectroscopy (FTIR) of the red wines assayed in duplicate (Syrah (Sy), Touriga Nacional (TN), Aragonês (Ar)). Mean values of the results of the analysis performed in 2014 and 2018 are presented.

\begin{tabular}{|c|c|c|c|c|c|c|}
\hline \multirow{2}{*}{$\begin{array}{c}\text { Year of Analysis } \\
\text { Modality }\end{array}$} & \multicolumn{3}{|c|}{2014} & \multicolumn{3}{|c|}{2018} \\
\hline & Mp & Control & Effect & $\mathbf{M p}$ & Control & Effect \\
\hline Specific Gravity & 0.992 & 0.992 & - & 0.992 & 0.991 & $* * *$ \\
\hline Alcoholic Strength (\% v/v) & 13.62 & 13.72 & * & 13.55 & 13.66 & * \\
\hline Total Dry Matter (g.L $\left.{ }^{-1}\right)$ & 30.3 & 29.3 & $* * *$ & 29.3 & 28.4 & ** \\
\hline Reducing Sugars (g. $\mathrm{L}^{-1}$ ) & 3.65 & 3.33 & $* * *$ & 3.33 & 3.03 & $* * *$ \\
\hline Total Acidity (g/L tartaric acid) & 5.25 & 5.22 & ns & 5.06 & 5.05 & ns \\
\hline Volatile Acidity (g/L acetic acid) & 0.32 & 0.32 & ns & 0.39 & 0.37 & ns \\
\hline $\mathrm{pH}$ & 3.482 & 3.468 & ns & 3.450 & 3.434 & ns \\
\hline Total Polyphenol Index & 51.50 & 50.17 & ns & 49.07 & 46.77 & ns \\
\hline Glycerol (g.L ${ }^{-1}$ ) & 5.90 & 5.48 & $* * *$ & 5.28 & 4.92 & $*$ \\
\hline
\end{tabular}

Level of significance, $\alpha \geq 0.05$; n.s.; not significant; ${ }^{*}$ significant $(\alpha<0.05)$; ${ }^{* *}$ very significant $(\alpha<0.01)$; ${ }^{* * *}$ highly significant $(\alpha<0.001)$.

The multivariate analysis of the 2014 and 2018 FTIR data are presented at Figure 2, showing the projection of the 34 wines obtained, in the space generated by the two first factors of the PCA, axes F1 and F2, which represents approximately $78.8 \%$ of the total data variability. These two first PCA factors allow the discrimination of all white varieties, associated with higher values of factor one, and of three red varieties namely Merlot, Touriga Nacional and Castelão with higher values of factor 2 . Concomitantly, the projections of all the modalities/year of Alv, Vio, SN, FP, Ver, Cast, Me and TN wines seem to aggregate in individualized spaces (represented by ellipses at Figure 2). For the majority of the grapevine varieties, Mp modality wines showed lower values regarding the F1 axis, either for 2014 or 2018, indicating that Mp wines tended to present higher values of TDM, Gly, IPT, RS and pH, which are the attributes most correlated with this axis, respectively $-0.977,-0.964,-0.945,-0.876$ and -0.838 . The exception was observed for Viognier, Fernão Pires, Cabernet Sauvignon and Caladoc, without clear tendencies along the F1 axis. Mp modality wines of Touriga Nacional, Aragonês, Jaen, Castelão, Tinta Barroca, Verdelho, Seara Nova and Alvarinho varieties, were positioned with lower values of F2 when compared to C modality. AS was the most correlated attribute with the F2 axis (0.891), meaning that Mp wines tended to present lower AS. These results, obtained with PCA of the 34 wines, corroborate the statistically proven effect of M. pulcherrima on TDM, Gly, RS and AS, observed for the three varieties assayed in duplicate (Table 2) and are in agreement with the results obtained by other authors in laboratory scale experiments [2,5]. 




Figure 2. Plot of the first and second principal components obtained from the principal component analysis (PCA) of the FTIR data, for each varietal wine. Designations used are letters for grape variety followed by $\mathrm{Mp}$ for co-inoculation with $\mathrm{M}$. pulcherrima, and $\mathrm{C}$ for control, followed by the replication number (when applied). Last numbers correspond to the year of FTIR analysis (2014 or 2018). The percentage of variation explained by each PC is $55.9 \%$ for Factor 1 and $22.8 \%$ for Factor 2.

In terms of wine's evolution from 2014 to 2018, there is a general tendency observed both in Mp and C wines (red and white), of an increase along F1 and F2 axis. Despite a decrease of AS over four years of aging, higher values regarding F2 axis were obtained, which can be explained by the inverse variation of VA over time, as this last attribute is the second most correlated with this axis (0.747). These results show that the wines evolved in a similar direction, showing no clear influence of $\mathrm{Mp}$ over evolution.

Discrimination sensory analysis is best suited to evaluate if two or more products are sensory different, and this it was performed on the wines in 2014, to detect eventual differences between the modalities, either for a particular attribute or the overall quality [16]. Triangle tests results are 
presented in Table 3, namely the number of correct responses obtained and the minimum number of correct responses required for significance at 0.10 risk level for the corresponding number of responses (ISO 4120:2004). A greater or equal number of correct responses were obtained for Verdelho, Caladoc and Tinta Barroca wines, revealing perceptible sensory differences between the $\mathrm{Mp}$ and the control wine. Furthermore, an informal sensory evaluation of these wines was performed by an experienced group of enologists which mentioned Verdelho Mp wine as presenting intense aroma, characterized by ripe fruit with tropical notes, banana, pear and peach. Control wine showed stronger aromas of citrus, slight vegetal, anise, hay and clover, with a stronger acidity. Verdelho Mp wine was rounder, fatter, with greater volume, less acidity and with notes of salinity and minerality. Caladoc wines presented evident aroma of black fruit, chocolate and spicy notes. Control with violet aromas and good persistence, was rounder and with tannins slightly acidic. Mp wine was similar but with more fragrant and floral attributes, gaining elegance and minerality, standing out the acidity and maintaining a good persistence. Tinta Barroca gave rise to wines with great aromatic profile, the $C$ wine presenting dried and red fruit, raspberry and cherry aromas and strong tannins. Mp wine presented similar aromatic profile, but more evident fruit freshness, less aggressive tannins and greater acid sensation.

Table 3. Triangle test results and the minimum number of correct responses required.

\begin{tabular}{cccc}
\hline Wine Variety & Total Responses & Correct Responses & $\begin{array}{c}\text { Minimum Correct } \\
\text { Responses }(\boldsymbol{\alpha}=\mathbf{0 , 1 0 )})^{(\mathbf{1})}\end{array}$ \\
\hline Alvarinho & 18 & 7 & 10 \\
Fernão Pires & 20 & 7 & 11 \\
Viognier & 21 & 9 & 11 \\
Seara Nova & 18 & 9 & 10 \\
Verdelho & 18 & 10 & 10 \\
Merlot & 20 & 8 & 11 \\
Cabernet Sauvignon & 19 & 8 & 10 \\
Caladoc & 19 & 7 & 10 \\
Castelão & 19 & 7 & 10 \\
Jaen & 20 & 10 & 11 \\
Tinta Barroca & 19 & 70 \\
\hline
\end{tabular}

(1) Values extracted from ISO 4120:2004.

Results of the ranking tests performed to Syrah, Touriga Nacional and Aragonês wines vinified in duplicate are shown in Table 4. No significant differences were detected between Mp and Control wines for the attributes color intensity, flavor quality, taste quality and overall quality.

Table 4. Sum of the ordinations obtained for Mp and control wines and their replicas for Syrah, Touriga Nacional and Aragonês varieties and the value of the resulting Friedman test (F).

\begin{tabular}{cccccc}
\hline Variety & Wine & Color Intensity & Flavor Quality & Taste Quality & Overall Quality \\
\hline \multirow{5}{*}{ Syrah } & Mp 1 & 21 & 17 & 19 & 18 \\
& Mp 2 & 30 & 27 & 31 & 28 \\
& Control 1 & 22 & 29 & 22 & 26 \\
& Control 2 & 27 & 27 & 28 & 28 \\
& $F$ & 3.2 & 5.3 & 5.4 & 4.1 \\
\hline \multirow{5}{*}{ Touriga } & Mp 1 & 27 & 25 & 27 & 24 \\
Nacional & Mp 2 & 24 & 29 & 25 & 27 \\
& Control 1 & 27 & 24 & 26 & 26 \\
& Control 2 & 22 & 22 & 22 & 23 \\
& $F$ & 1.6 & 0.8 & 0.6 \\
Aragonês & Mp 1 & 27 & 25 & 22 & 30 \\
& Mp 2 & 28 & 26 & 30 & 27 \\
& Control 1 & 26 & 26 & 26 & 20 \\
& Control 2 & 19 & 23 & 22 & 3.5 \\
\hline
\end{tabular}

Ranking test: Minimum $=1$, maximum $=4 ; \chi^{2}$ tab $(3 \mathrm{gl} ; 99.5 \%)=7.81$; calc $<$ tab indicate not significant difference. 
The sensory discrimination tests performed showed that only three out of the 14 varieties assayed with M. pulcherrima originated wines that were significantly different from the control wines. Although the majority of the wines were similar from a sensory point of view, they presented differences at the composition level, and these results are in agreement with those obtained by Chen et al. [3] and Varela et al. [8].

\section{Conclusions}

The addition of $M$. pulcherrima has been recommended primarily for fermentation of white grape varieties. This study presents a comparative pilot-scale winery assay using this yeast in mixed fermentation for the production of elementary white and red wines, influencing the characteristics of both types of wine. A general tendency encountered was the reduction in alcohol content and an increase in glycerol, reducing sugars and total dry matter, which are all valorized features in the consumer wine market. Discrimination tests seemed quite adequate to detect sensory differences between modalities, revealing differences for three of the grape varieties assayed. The different results obtained for the tested varieties emphasized the need to include various grape varieties in studies with non-Saccharomyces yeasts.

Author Contributions: Conceptualization, F.L.D.; formal analysis, R.E., F.L.D. and M.M.B.-C.; investigation, F.L.D. and M.M.B.-C.; methodology, F.L.D.; writing-original draft, F.L.D., M.M.B.-C. and R.E.

Funding: This research received no external funding.

Acknowledgments: R. Egipto had a FCT scholarship, SFRH/BD/128847/2017. The authors thank Patrícia Marques for collaboration in the setup of the triangle and ranking tests, and the tasting panel of INIAV-Dois Portos. Work supported by UID/MULTI/04046/2019 Research Unit grant from FCT, Portugal (to BioISI).

Conflicts of Interest: The authors declare no conflict of interest

\section{References}

1. Teixeira, A.; Caldeira, I.; Duarte, F.L. Molecular and enological characterization of Touriga Nacional non-Saccharomyces yeasts. J. Appl. Microbiol. 2015, 118, 658-671. [CrossRef] [PubMed]

2. Rossouw, D.; Bauer, F.F. Exploring the phenotypic space of non-Saccharomyces wine yeast biodiversity. Food Microbiol. 2016, 55, 32-46. [CrossRef] [PubMed]

3. Chen, K.; Escott, C.; Loira, I.; del Fresno, J.M.; Morata, A.; Tesfaye, W.; Calderon, F.; Suárez-Lepe, J.A.; Han, S.; Benito, S. Use of non-Saccharomyces yeasts and oenological tannin in red winemaking: Influence on colour, aroma and sensorial properties of young wines. Food Microbiol. 2018, 69, 51. [CrossRef] [PubMed]

4. Ribéreau-Gayon, P.; Dubourdieu, D.; Donèche, B.; Lonvaud, A. Handbook of Enology, The Microbiology of Wine and Vinifications, 2nd ed.; John Wiley \& Sons: Chichester, UK, 2006; Volume 1, p. 497.

5. Liu, P.T.; Lu, L.; Duan, C.Q.; Yan, G.L. The contribution of indigenous non-Saccharomyces wine yeast to improved aromatic quality of Cabernet Sauvignon wines by spontaneous fermentation. LWT Food Sci. Technol. 2016, 71, 356-363. [CrossRef]

6. Comitini, F.; Gobbi, M.; Domizio, P.; Romani, C.; Lencioni, L.; Mannazzu, I.; Ciani, M. Selected non-Saccharomyces wine yeasts in controlled multistarter fermentations with Saccharomyces cerevisiae. Food Microbiol. 2011, 28, 873. [CrossRef] [PubMed]

7. Sadoudi, M.; Tourdot-Marechal, R.; Rousseaux, S.; Steyer, D.; Gallardo-Chacon, J.J.; Ballester, J.; Vichi, S.; Guerin-Schneider, R.; Caixach, J.; Alexandre, H. Yeast-yeast interactions revealed by aromatic profile analysis of Sauvignon Blanc wine fermented by single or co-culture of non-Saccharomyces and Saccharomyces yeasts. Food Microbiol. 2012, 32, 243-253. [CrossRef] [PubMed]

8. Varela, C.; Barker, A.; Tran, T.; Borneman, A.; Curtin, C. Sensory profile and volatile aroma composition of reduced alcohol Merlot wines fermented with Metschnikowia pulcherrima and Saccharomyces uvarum. Int. J. Food Microbiol. 2017, 252, 1-9. [CrossRef] [PubMed]

9. Du Plessis, H.; du Toit, M.; Nieuwoudt, H.; van der Rijst, M.; Kidd, M.; Jolly, N. Effect of Saccharomyces, non-Saccharomyces yeasts and malolactic fermentation strategies on fermentation kinetics and flavor of Shiraz Wines. Fermentation 2017, 3, 64. [CrossRef] 
10. Contreras, A.; Curtin, C.; Varela, C. Yeast population dynamics reveal a potential 'collaboration' between Metschnikowia pulcherrima and Saccharomyces uvarum for the production of reduced alcohol wines during Shiraz fermentation. Appl. Microbiol. Biotechnol. 2015, 99, 1885-1895. [CrossRef] [PubMed]

11. Barbosa, C.; Lage, P.; Esteves, M.; Chambel, L.; Mendes-Faia, A.; Mendes-Ferreira, A. Molecular and phenotypic characterization of Metschnikowia pulcherrima strains from Douro wine region. Fermentation 2018, 4, 8. [CrossRef]

12. Varela, C. The impact of non-Saccharomyces yeasts in the production of alcoholic beverages. Appl. Microbiol. Biotechnol. 2016, 100, 9861-9874. [CrossRef] [PubMed]

13. OIV. Compendium of International Methods of Wine and Must Analysis; International Organization of Vine and Wine: Paris, France, 2014; Volume 1, p. 497.

14. Kunert, J.; Meyners, M. On the triangle test with replications. Food Qual. Pref. 1999, 10, 477-482. [CrossRef]

15. Sauvageot, F. Principes des techniques d'analyse. In Techniques D'analyse Sensorielle et de Controle Dans les Industries Agro-alimentaires; Linden, G., Ed.; Lavoisier Tec. \& Doc.: Paris, France, 1981; Volume 2, pp. 327-390.

16. Strigler, F.; Touraille, C.; Sauvageot, F.; Barthélémy, J.; Issanchou, S. Les épreuves discriminatives et descriptives. In Évaluation Sensorielle. Manuel Méthodologique; Depledt, F., Ed.; Lavoisier: Paris, France, 2009; Chapter 4; pp. 99-197.

(C) 2019 by the authors. Licensee MDPI, Basel, Switzerland. This article is an open access article distributed under the terms and conditions of the Creative Commons Attribution (CC BY) license (http://creativecommons.org/licenses/by/4.0/). 